\title{
Gain enhancement of linear four element microstrip antenna array
}

\author{
K. Prahlada Rao ${ }^{1 *}$, Vani R.M ${ }^{2}$ and P.V.Hunagund ${ }^{2}$ \\ Department of PG Studies and Research in Applied Electronics, Gulbarga University, Gulbarga, India ${ }^{1}$ \\ Assistant Professor, University Science Instrumentation Center, Gulbarga University, Gulbarga, India ${ }^{2}$
}

(C2018 ACCENTS

\begin{abstract}
This paper explains the impact of electromagnetic band gap structures towards the improvement of gain of four element microstrip antenna array. The conventional four element microstrip antenna array is resonating at a fundamental frequency of $5.53 \mathrm{GHz}$. The gain and the mutual coupling values at the resonant frequency of $5.53 \mathrm{GHz}$ are 6.81, -16.95 , -14.22 and $-17.30 \mathrm{~dB}$ respectively. The proposed antenna array with I-shape slot EBG structure in the ground plane and fractal patch EBG structure on the surface produces reduced mutual coupling of $-38.42,-32.10$ and $-36.94 \mathrm{~dB}$ at 5.53 GHz. An enhanced gain of $9.42 \mathrm{~dB}$ is produced at $5.53 \mathrm{GHz}$. The proposed antenna array produces a virtual size reduction of $77.92 \%$ with sizable reduction in back lobe radiation. The dielectric substrate used is FR-4 glass epoxy with dielectric constant 4.2 and loss tangent 0.0245. The antenna arrays are designed using mentor graphics IE3D software and measured results are obtained using vector network analyzer.
\end{abstract}

\section{Keywords}

Bandwidth, Electromagnetic band gap structures, Gain, Resonant frequency.

\section{Introduction}

Antennas play an efficient role in modern communication devices and systems in creating a better transmission link between the transmitter and receiver. The type and performance of antennas depend on the excitation method and the transmission lines employed. The functioning of antennas particularly the microwave antennas is primarily based on electromagnetic theory. A proper and meticulous design of antennas is very much required to reduce the complexities involved in system performance and increase the efficiency of the rate of transmission and reception on the communication link [1-5].

In the microwave frequency range the most preferred transmission line employed is the microstrip line as the amount of parasitic inductance and capacitance produced is very much lesser than the normal lumped elements. The structure of microstrip antenna is similar to that of microstrip line.

In its simplest configuration, a microstrip antenna is a printed type of antenna which is made of a dielectric substrate placed between the radiating patch and finite ground.

\footnotetext{
*Author for correspondence
}

These antennas are widely used in systems where high level of compactness, low cost, ease of fabrication and installation are the benchmarks. On the other side of the coin, they suffer from few demerits like narrow bandwidth and surface wave excitation particularly noticeable in multi element microstrip antennas. This has a serious consequence on the mutual coupling between the antenna elements. Hence an unusual procedure or approach or technique is very much required to be implemented to solve this detrimental problem [6-12].

Electromagnetic band gap (EBG) structures are band stop structures which are periodic in nature. EBG structures have gained immense popularity and are being widely employed to give an appreciable decrease in interference between the individual antennas. These structures can be laid either on the ground plane or on the surface of the microstrip antennas [13-15].

\section{Conventional antenna array}

The conventional antenna array is designed at the frequency of $6 \mathrm{GHz}$. The height of the substrate is 1.6 $\mathrm{mm}$. The conventional microstrip antenna array (CMAA) consists of four identical radiating patches fed by corporate feeding technique. Each of the radiating patches is rectangular in shape and the dimensions are $15.73 \mathrm{~mm} \times 11.76 \mathrm{~mm}$. The adjacent 
antenna elements are separated by a distance of $\lambda / 4$, where $\lambda$ is the wavelength calculated at the design frequency of $6 \mathrm{GHz}$. The schematic of CMAA is shown in Figure 1. The dimensions of the finite ground plane are equal to $122.5 \mathrm{~mm} \times 51.5 \mathrm{~mm}$. The feed and the quarter wave transformer have the dimensions of $6.52 \mathrm{~mm} \times 3.05 \mathrm{~mm}$ and $6.47 \times 0.47$ $\mathrm{mm}$. The dimensions of the other parts of the schematic depicted in Figure 1 are tabulated in Table 1

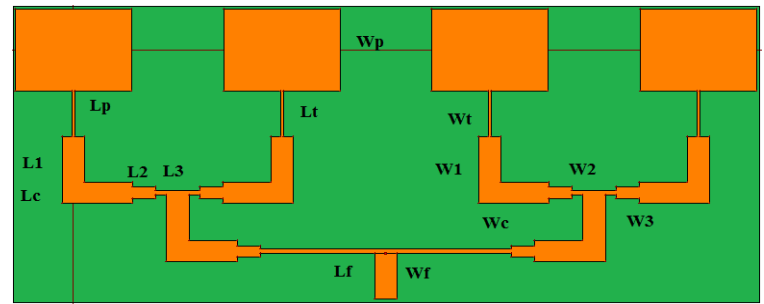

Figure 1 Schematic of CMAA

Table 1 Parameter values of CMAA

\begin{tabular}{ll}
\hline Parameter & Value(Mm) \\
\hline Length of the patch (Lp) & 15.73 \\
Width of the patch (Wp) & 11.76 \\
Length of the quarter wave transformer (Lt) & 6.47 \\
Width of the quarter wave transformer (Wt) & 0.47 \\
Length of the $50 \Omega$ line (L1) & 6.52 \\
Width of the $50 \Omega$ line (W1) & 3.05 \\
Length of the coupler (Lc) & 3.05 \\
Width of the coupler (Wc) & 3.05 \\
Length of the $70 \Omega$ line (L2) & 6.54 \\
Width of the $70 \Omega$ line (W2) & 1.62 \\
Length of the $100 \Omega$ line (L3) & 6.56 \\
Width of the $100 \Omega$ line (W3) & 0.70 \\
Length of the feed line (Lf) & 6.52 \\
Width of the feed line (Wf) & 3.05 \\
\hline
\end{tabular}

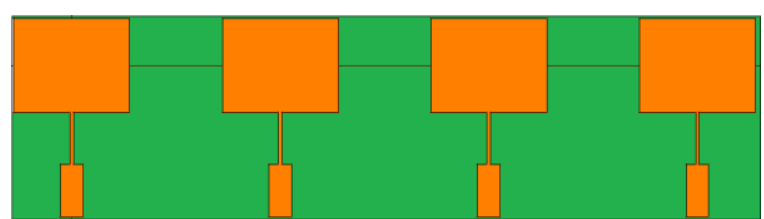

Figure 2 Schematic of CMAA for the measurement of mutual coupling

\section{Proposed antenna array}

The proposed microstrip antenna array is designed by loading the EBG structures both in the ground plane and on the surface of CMAA. The EBG structure employed on the surface are in the same plane as that of the four rectangular radiating patches and placed between the adjacent radiating patches. The ground plane is replaced with a matrix of 4 rows and 9 152 columns of I shape slot EBG structure. On the other hand, the EBG structure integrated on the surface is a matrix of 5 rows and 2 columns of fractal shape patch. The unit cells of the EBG structures are depicted in Figure 3.

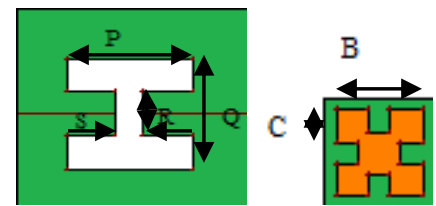

Figure 3 Schematic of the unit cells of the EBG structures

In Figure 3, the schematic on the left side depicts the unit cell of the EBG structure in the ground plane and the one on the right side depicts the unit cell of the EBG structure on the surface. The dimensions of the unit cells shown in Figure 3 are $\mathrm{P}=9 \mathrm{~mm}, \mathrm{Q}=9 \mathrm{~mm}$, $\mathrm{R}=3.75 \mathrm{~mm}$ and $\mathrm{S}=2 \mathrm{~mm}, \mathrm{~B}=9 \mathrm{~mm}$ and $\mathrm{C}=1.5 \mathrm{~mm}$ respectively.

The EBG structures employed to design the proposed antenna array are shown in Figures 4 and 5. Figure 4 depicts the EBG structure loaded in the ground plane and Figure 5 depicts the EBG structure placed on the surface of CMAA.

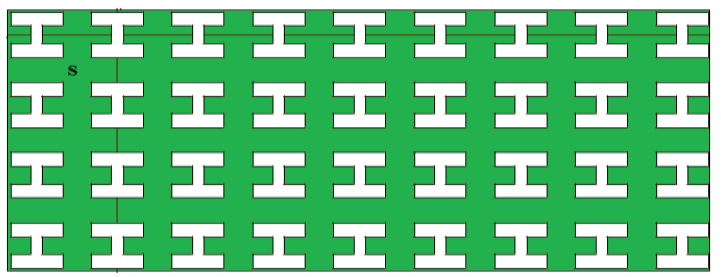

Figure 4 Schematic of I shape slot EBG structure used in the ground plane

In Figure 4, $\mathrm{S}$ is the distance between the adjacent unit cells of the EBG structure and is equal to $5 \mathrm{~mm}$ along the $\mathrm{x}$-axis and y-axis. In Figure 5, the unit cells of the fractal patch EBG structure are separated by $\mathrm{Y}=1 \mathrm{~mm}$ along the $\mathrm{x}$-axis and $\mathrm{y}$-axis.

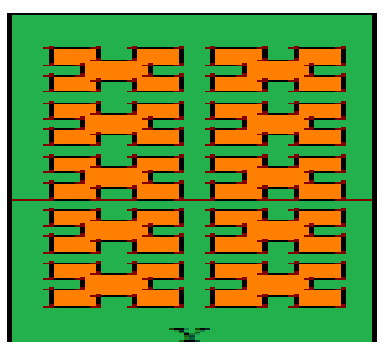

Figure 5 Schematic of fractal patch EBG structure used on the surface 
Figure 6 shows the schematic of the proposed antenna array

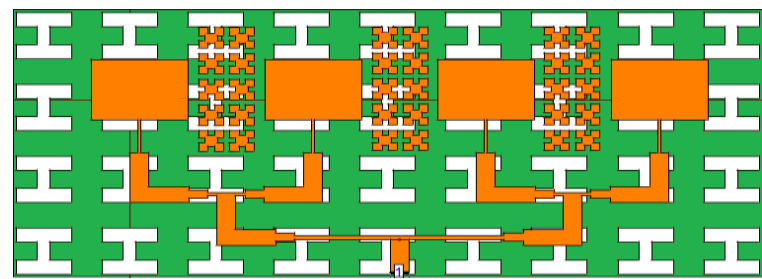

Figure 6 Schematic of the proposed antenna array

The parameter mutual coupling of the proposed antenna array is measured by loading the EBG structures mentioned in Figures 4 and 5 in the ground plane and on the surface of the schematic shown in Figure 2. The schematic of such a setup is depicted in Figure 7

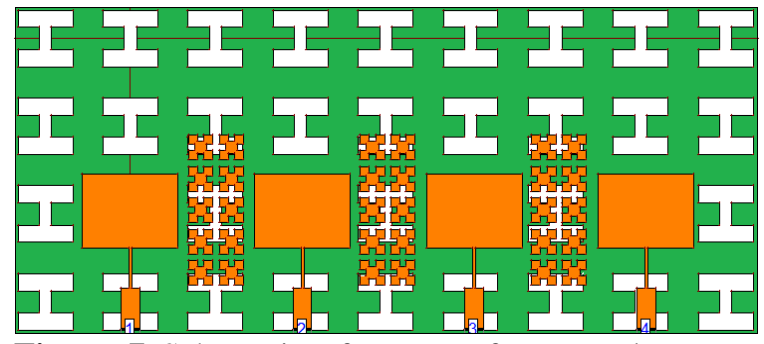

Figure 7 Schematic of set up of proposed antenna array for the measurement of mutual coupling

\section{Photographs of fabricated antenna arrays}

The photographs of the fabricated antennas of CMAA and the proposed antenna array are shown in Figures 8, 9, 10 and 11 respectively.

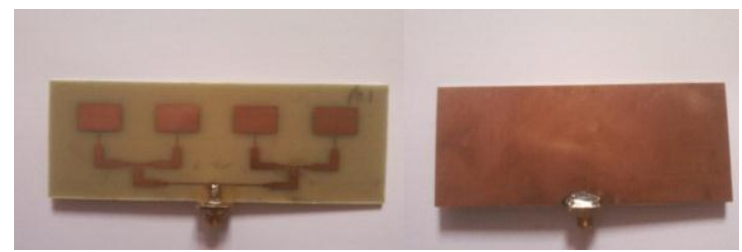

(a) Front view

(b) Rear view

Figure 8 Photograph of CMAA

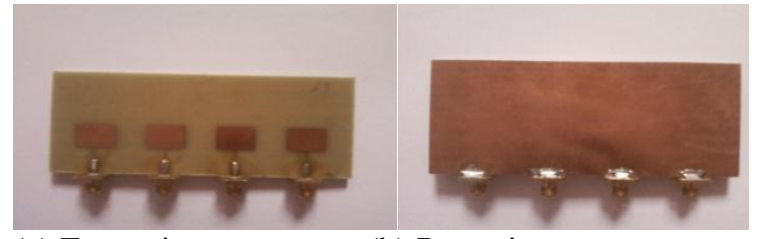

(a) Front view

(b) Rear view

Figure 9 Photograph of arrangement of CMAA for mutual coupling measurement

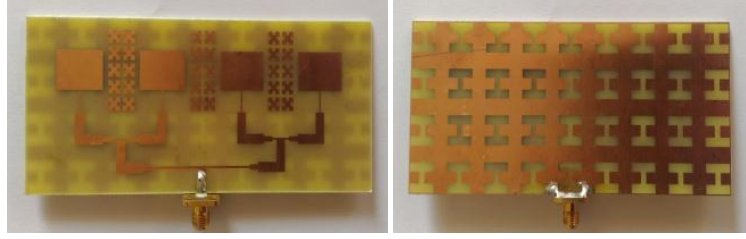

(a) Front view

(b) Rear view

Figure 10 Photograph of proposed antenna array

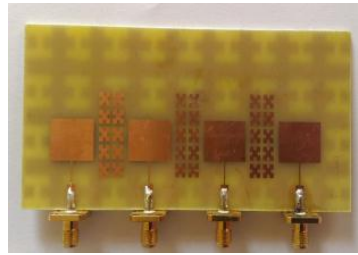

(a) Front view

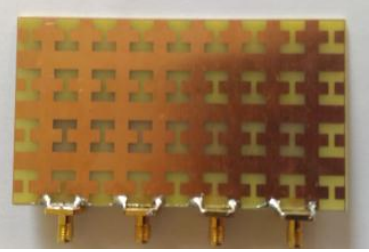

(b) Rear view
Figure 11 Photograph of arrangement of proposed antenna array for mutual coupling measurement

\section{Results}

The performance of CMAA is compared with that of the proposed antenna array in terms of parameters return loss, resonant frequency, bandwidth, mutual coupling, gain, forward power, backward power, front to back ratio and virtual size reduction. The parameter return loss is one of the most important parameters to examine the performance of microstrip antenna arrays. It is designated by the S-parameter $\mathrm{S}_{11}$. The plots of return loss and mutual coupling versus frequency are depicted in Figures 12, 13 and 14 respectively.

From Figures 12, 13 and 14, the CMAA designed at the frequency of $6 \mathrm{GHz}$, is resonating at the fundamental frequency of $5.53 \mathrm{GHz}$ with a return loss of $-21.06 \mathrm{~dB}$. Resonant frequency is measured as the frequency at which the return loss is least between the points where the return loss graph is crossing the $-10 \mathrm{~dB}$ value. The other important parameter that can be extracted from the return loss graph is the bandwidth. It is calculated by subtracting the lower frequency from the upper frequency where the return loss crosses $-10 \mathrm{~dB}$ values. The CMAA thus possesses a bandwidth equal to $273 \mathrm{MHz}$. The bandwidth (\%) is calculated by using the formula

$\frac{\text { Bandwidth }}{\text { Resonant frequency }} \times 100 \%$

Hence the bandwidth (\%) of CMAA is equal to 4.89 $\%$. From Figures 12, 13 and 14, the experimental values of mutual coupling $\left(\mathrm{S}_{21}, \mathrm{~S}_{31}\right.$ and $\left.\mathrm{S}_{41}\right)$ measured at the resonant frequency of $5.53 \mathrm{GHz}$ are equal to $-16.95,-14.22$ and $-17.30 \mathrm{~dB}$ respectively. 
These values of mutual coupling are considered to be very severe. More importantly, the return loss and mutual coupling graphs are crossing each other at the resonant frequency of $5.53 \mathrm{GHz}$. This has a serious effect on the interference between the transmitting antenna 1 and each of the receiving antennas 2, 3 and 4, which leads to improper transfer or loss of electromagnetic waves from the antenna 1 to antennas 2, 3 and 4 or vice-versa. After the EBG structures are loaded in the ground plane and on the surface of CMAA, the following variations in the plots of return loss and mutual coupling of proposed antenna array are observed as depicted in Figures 15, 16 and 17.

From Figures 12, 13 and 14, the CMAA designed at the frequency of $6 \mathrm{GHz}$, is resonating at the fundamental frequency of $5.53 \mathrm{GHz}$ with a return loss of $-21.06 \mathrm{~dB}$. Resonant frequency is measured as the frequency at which the return loss is least between the points where the return loss graph is crossing the $-10 \mathrm{~dB}$ value. The other important parameter that can be extracted from the return loss graph is the bandwidth. It is calculated by subtracting the lower frequency from the upper frequency where the return loss crosses $-10 \mathrm{~dB}$ value. The CMAA thus possesses a bandwidth equal to $273 \mathrm{MHz}$. The bandwidth (\%) is calculated by using the formula

$\frac{\text { Bandwidth }}{\text { Resonant frequency }} \times 100 \%$

Hence the bandwidth (\%) of CMAA is equal to 4.89 $\%$. From Figures 12, 13 and 14, the experimental values of mutual coupling $\left(\mathrm{S}_{21}, \mathrm{~S}_{31}\right.$ and $\left.\mathrm{S}_{41}\right)$ measured at the resonant frequency of $5.53 \mathrm{GHz}$ are equal to $-16.95,-14.22$ and $-17.30 \mathrm{~dB}$ respectively. These values of mutual coupling are considered to be very severe. More importantly, the return loss and mutual coupling graphs are crossing each other at the resonant frequency of $5.53 \mathrm{GHz}$. This has a serious effect on the interference between the transmitting antenna 1 and each of the receiving antennas 2, 3 and 4, which leads to improper transfer or loss of electromagnetic waves from the antenna 1 to antennas 2, 3 and 4 or vice-versa.

After the EBG structures are loaded in the ground plane and on the surface of CMAA, the following variations in the plots of return loss and mutual coupling of proposed antenna array are observed as depicted in Figures 15, 16 and 17.

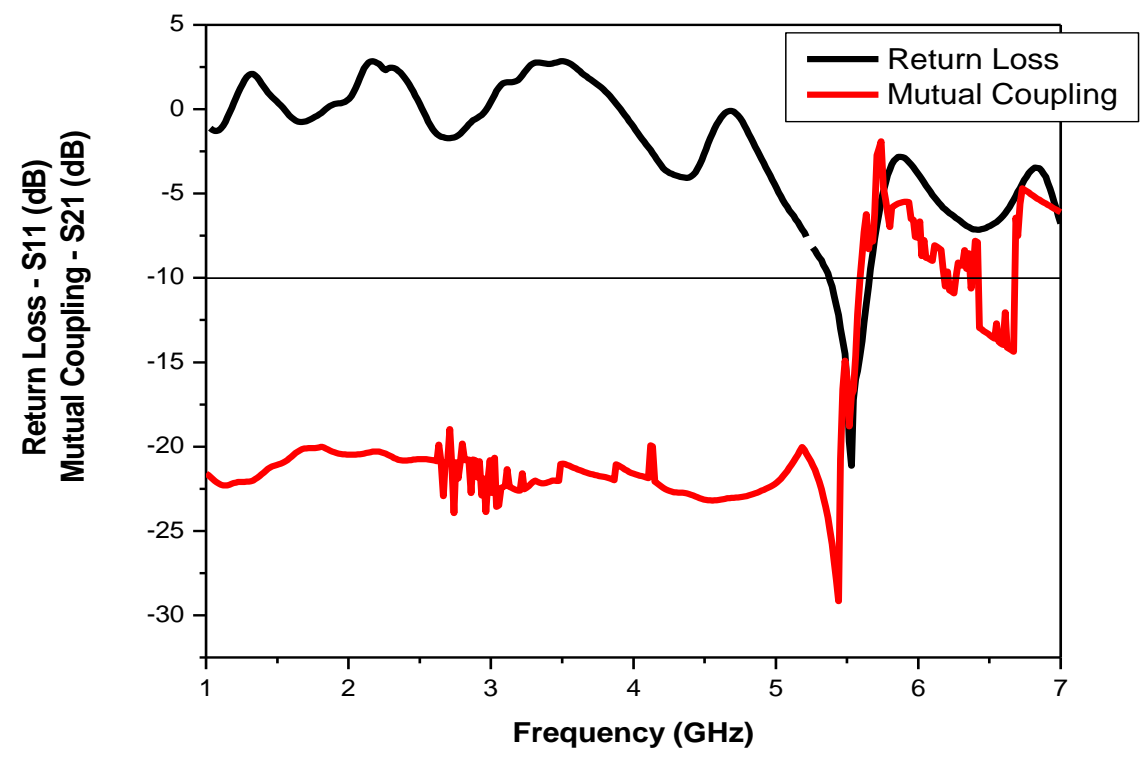

Figure 12 Plot of Return Loss and Mutual Coupling $\left(S_{21}\right)$ versus Frequency of CMAA 


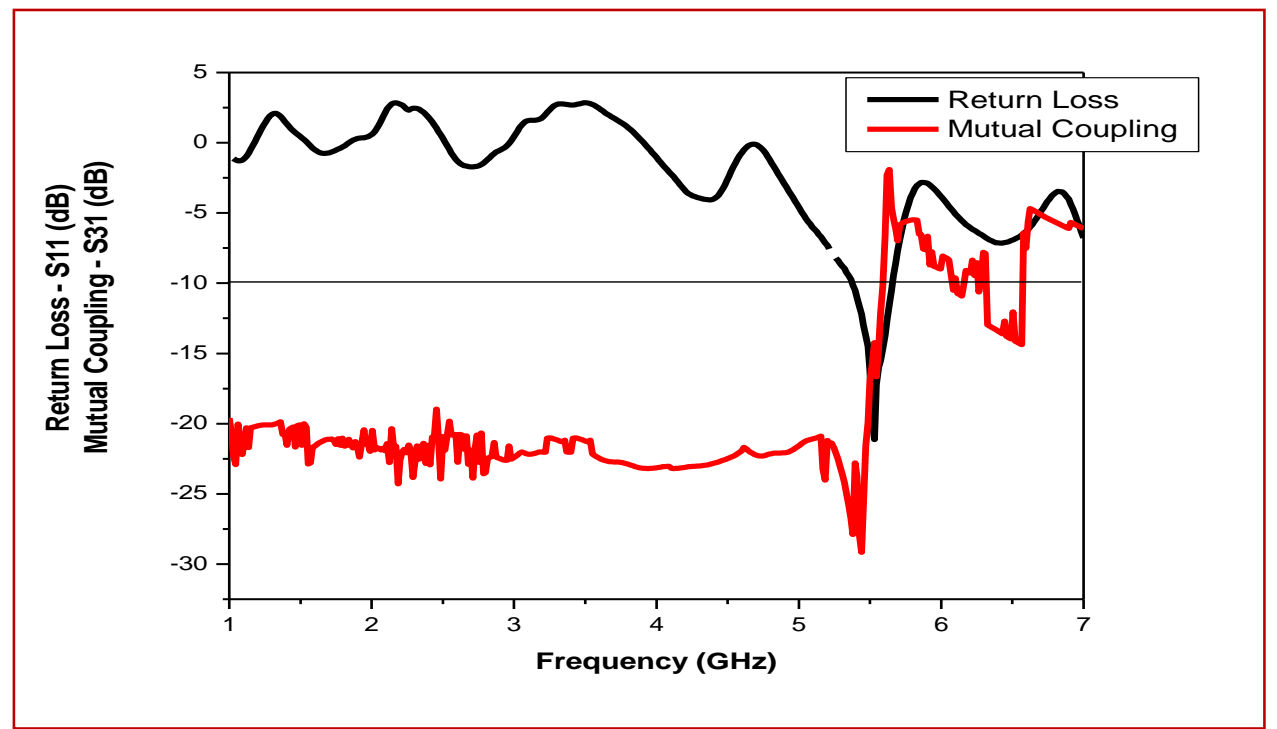

Figure 13 Plot of return loss and mutual coupling $\left(\mathrm{S}_{31}\right)$ versus frequency of CMAA

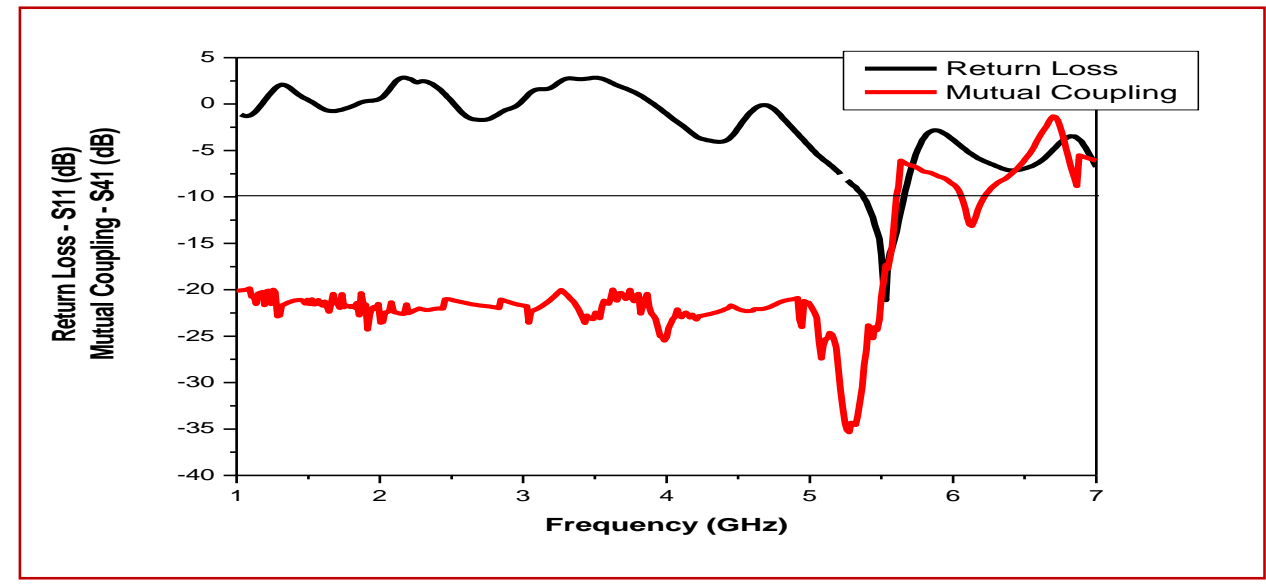

Figure 14 Plot of return loss and mutual coupling $\left(\mathrm{S}_{41}\right)$ versus frequency of CMAA

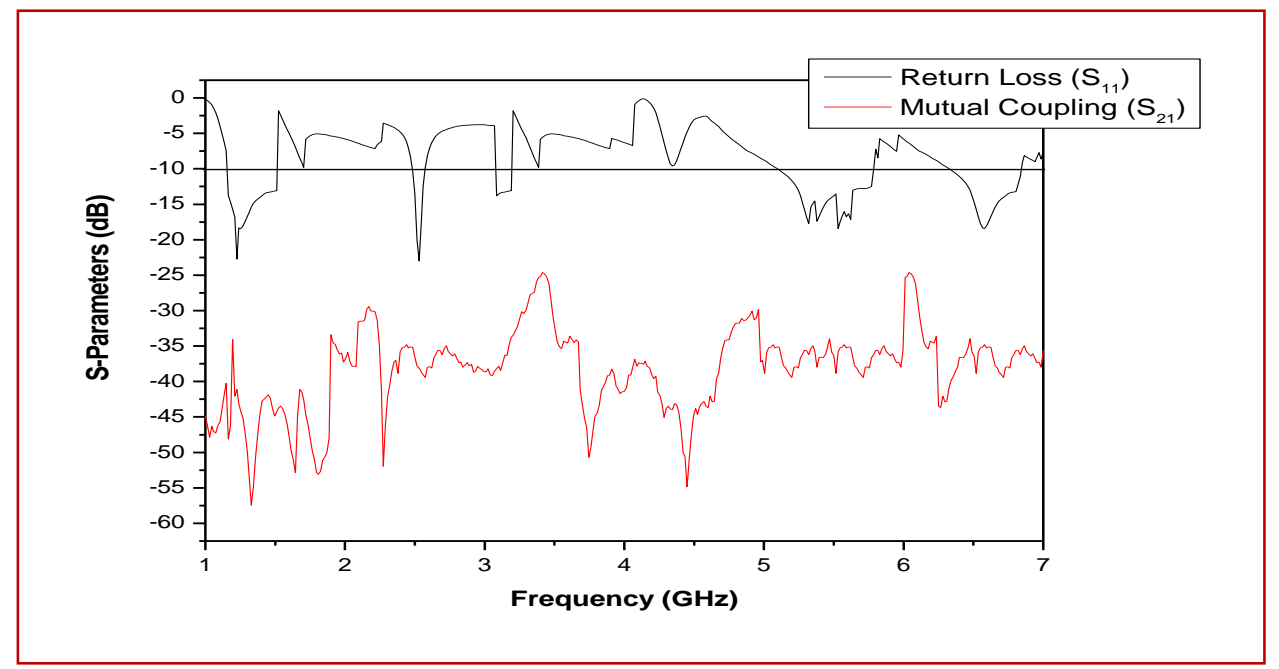

Figure 15 Plot of return loss and mutual coupling $\left(S_{21}\right)$ versus frequency of proposed antenna array 


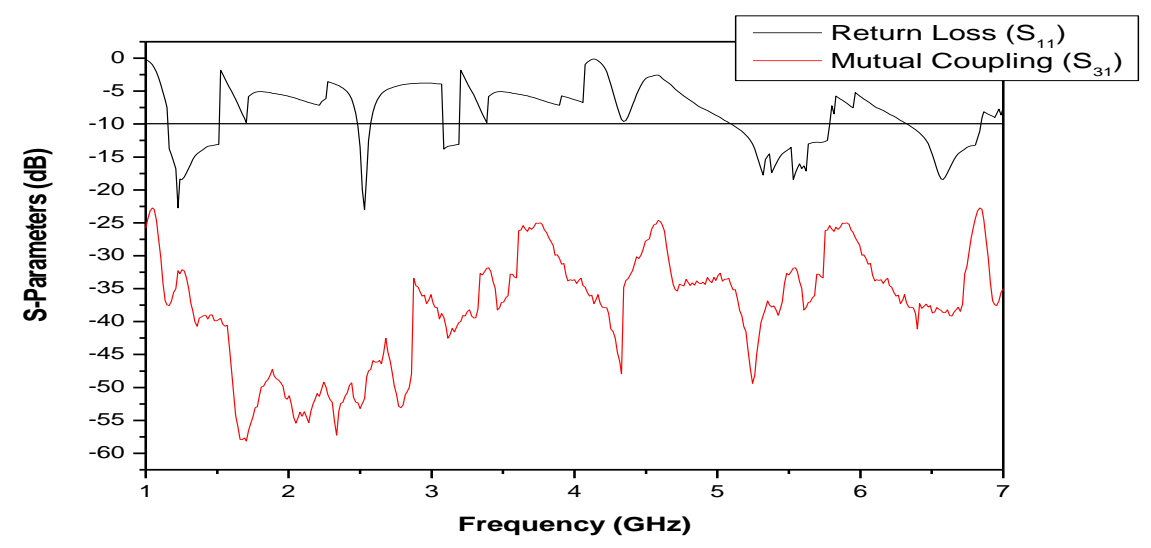

Figure 16 Plot of return loss and mutual coupling $\left(S_{31}\right)$ versus frequency of proposed antenna array

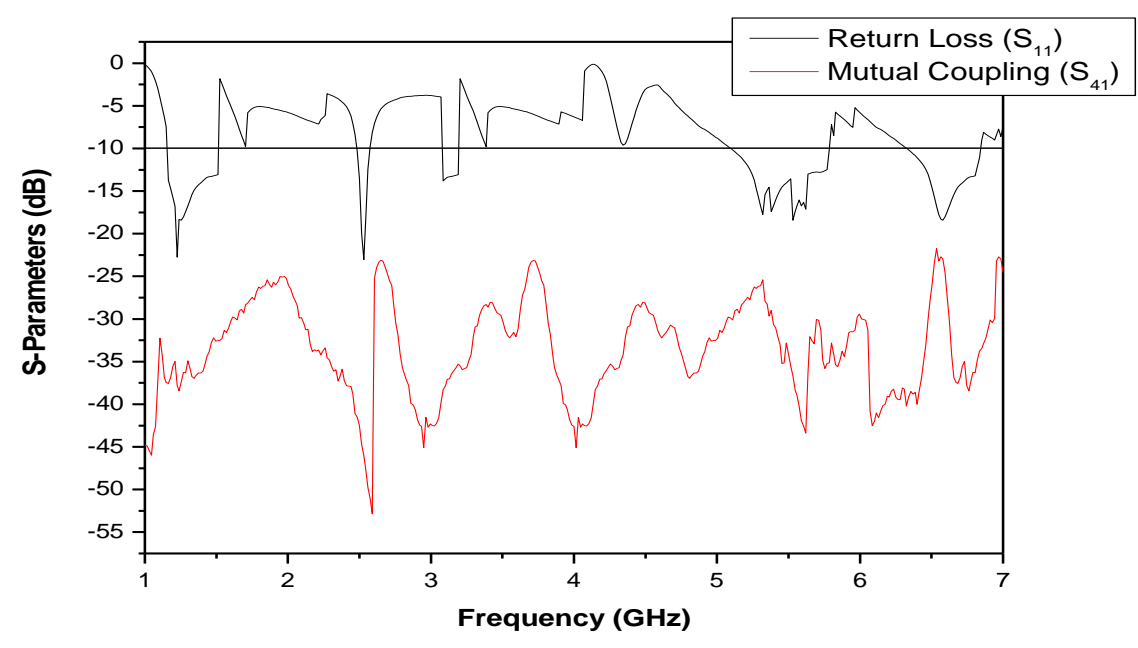

Figure 17 Plot of return loss and mutual coupling $\left(\mathrm{S}_{41}\right)$ versus frequency of proposed antenna array

Figures 15, 16 and 17 depict that the proposed microstrip antenna array is resonating at five frequencies $-1.219,2.533,3.071,5.53$ and $6.56 \mathrm{GHz}$ respectively. It produces bandwidth at the corresponding resonant frequencies equal to 346 , 108, 107, 704 and $526 \mathrm{MHz}$ respectively. Thus the overall bandwidth $(\%)$ of the proposed antenna array is equal to $56.83 \%$ as against $4.89 \%$ of CMAA. The measured values of mutual coupling $\left(\mathrm{S}_{21}, \mathrm{~S}_{31}\right.$ and $\left.\mathrm{S}_{41}\right)$ at the resonant frequency of $5.53 \mathrm{GHz}$ are equal to $38.42,-32.10$ and $-36.16 \mathrm{~dB}$ respectively.

From the above discussion we see that the proposed antenna array has an enhanced overall bandwidth (\%) compared to its counterpart CMAA. Apart from the substantial decrease in the mutual coupling values, the plots of return loss and mutual coupling of the proposed antenna array are no more overlapping at the resonant frequency of $5.53 \mathrm{GHz}$. Hence the amount of interference, between the transmitting antenna 1 and receiving antennas 2, 3 and 4 is minimized.

The parameter Gain is calculated by using the formula

$G=20 \log _{10}\left(\frac{4 \pi R}{\lambda}\right)+10 \log _{10} \frac{P r}{P t}-G t$

where,

Pt is the transmitted power.

$\mathrm{Pr}$ is the received power.

$\mathrm{R}$ is the distance between the transmitting and the receiving antennas.

$\lambda$ is the wavelength at the resonant frequency of 5.53 
GHz.

Gt is the gain of the transmitting antenna.

$\mathrm{Gt}$ is given by the formula

$G t=10 \log _{10} G s$

$G s=\frac{2 \pi a b}{\lambda^{2}}$

Where $\mathrm{a}$ and $\mathrm{b}$ are the length and width of the standard pyramidal horn antenna used as the transmitting antenna. The dimensions $\mathrm{a}$ and $\mathrm{b}$ are equal to 24 and $14 \mathrm{~cm}$ respectively. The distance between the transmitting antenna (standard horn antenna) and the receiving antenna is given by the formula

$R \geq \frac{2 D^{2}}{\lambda}$

Where $\mathrm{D}$ is the larger dimension of the transmitting antenna equal to $24 \mathrm{~cm}$. The value of $\mathrm{R}=71.86 \mathrm{~m}$. The transmitted and received powers in the case of CMAA are equal to $8.7 \mu \mathrm{W}$ and $12.414 \mathrm{nW}$ respectively. Substituting the parameter values in equation 1), the gain of CMAA is equal to $6.81 \mathrm{~dB}$. In the case of the proposed antenna array, the corresponding powers are equal to $8.7 \mu \mathrm{W}$ and 22.64 $\mathrm{nW}$ respectively. Substituting the parameter values in equation 1) the proposed antenna array produces a better gain equal to $9.42 \mathrm{~dB}$. Therefore, by employing the EBG structures, the gain of CMAA is increased by a value of $2.61 \mathrm{~dB}$. The CMAA and the proposed antenna arrays are resonating at fundamental frequencies equal to 5.53 and $1.21 \mathrm{GHz}$ as shown in Figures 12, 13, 14, 15, 16 and 17 respectively. The proposed antenna array is resonating at a lesser fundamental frequency compared to CMAA. Hence the virtual size reduction produced by the proposed antenna array is equal to $77.92 \%$.

To obtain the radiation patterns of CMAA and the proposed antenna array, the standard pyramidal horn antenna is employed as the transmitting antenna and the corresponding designed antenna arrays as the receiving antenna. Figure 18 shows the radiation properties of the microstrip antenna arrays designed in the form of a radiation pattern. The forward power is calculated at the angle of $90^{\circ}$ and the backward power at the angle of $270^{\circ}$.

From Figure 18, the amount of backward power radiated by CMAA and the proposed antenna array are -4.5 and $-8.3 \mathrm{~dB}$ respectively. Hence with the introduction of EBG structures, the back lobe radiation of CMAA is reduced considerably to -8.3 $\mathrm{dB}$. This shows that the proposed antenna array is radiating lesser power in the undesired direction compared to CMAA.

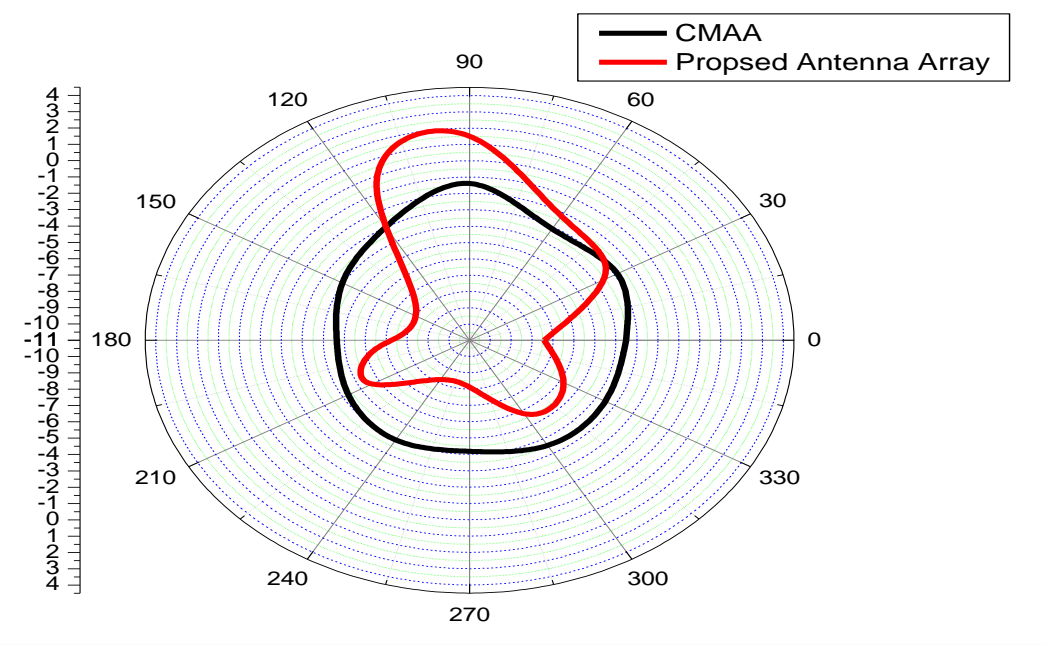

Figure 18 Plot of radiation patterns of CMAA and the proposed antenna array

The forward powers are measured in order to judge which antenna is radiating better in the desired direction. The measured forward powers of CMAA and the proposed antenna array are -2 and $-1.4 \mathrm{~dB}$ respectively. This depicts that the proposed antenna array is a better radiator than its competitor in the 157 desired direction. The parameter Front to Back ratio (FBR) is determined by subtracting the power radiated in the undesired direction from the power radiated in the desired direction. Hence the FBR values of CMAA and the proposed antenna arrays are 2.5 and $6.9 \mathrm{~dB}$ respectively. This confirms that the 
Rao et al.

FBR value of the proposed antenna array is greater than CMAA by $4.4 \mathrm{~dB}$.

\section{Summary of measured results}

Tables 2 and 3 depict the summarized measured results of CMAA and proposed antenna array.

Table 2 Summarized measured results

\begin{tabular}{llllll}
\hline $\begin{array}{l}\text { Type of } \\
\text { antenna }\end{array}$ & $\begin{array}{l}\text { Resonant } \\
\text { frequency } \\
\text { (GHZ) }\end{array}$ & Return loss (DB) & $\begin{array}{l}\text { Band } \\
\text { width } \\
\text { (MHZ) }\end{array}$ & $\begin{array}{l}\text { BAND } \\
\text { Width } \\
(\%)\end{array}$ & $\begin{array}{l}\text { GAIN } \\
\text { (DB) }\end{array}$ \\
\hline CMAA & 5.53 & -21.06 & 273 & 4.89 & 6.81 \\
Proposed & 1.21 & -22.59 & 346 & & \\
Antenna array & 2.53 & -22.73 & 108 & 56.83 & \\
& 3.07 & -13.96 & 107 & & \\
& 5.53 & -18.14 & 704 & & \\
\hline
\end{tabular}

Table 3 Summarized measured results

\begin{tabular}{|c|c|c|c|c|c|}
\hline $\begin{array}{l}\text { Type of } \\
\text { antenna }\end{array}$ & FBR & $\begin{array}{l}\text { Mutual } \\
\text { (DB) }\end{array}$ & coupling-S $\mathrm{S}_{21}$ & $\begin{array}{l}\text { Mutual coupling-S } S_{31} \\
\text { (DB) }\end{array}$ & $\begin{array}{l}\text { Mutual coupling-S } \\
\text { (DB) }\end{array}$ \\
\hline CMAA & 2.73 & -16.95 & & -14.22 & -17.30 \\
\hline $\begin{array}{l}\text { ProposedAntenna } \\
\text { Array }\end{array}$ & 9.91 & -38.42 & & -32.10 & -36.16 \\
\hline
\end{tabular}

The CMAA and the proposed antenna array are compared in terms of various performance parameters. The proposed antenna array is producing improved mutual coupling values, gain, bandwidth (\%), FBR and good reduction in back lobe radiation when compared to CMAA. An appreciable amount of virtual size reduction (\%) is also produced. Therefore, the performance of CMAA is improved in the presence of EBG structures than in the absence of EBG structures.

\section{Conclusion}

This paper investigates the behaviour of CMAA without and with EBG structures. The CMAA and the proposed antenna array are designed and fabricated and measured results conclude the capability of EBG structures. The proposed antenna array is yielding a high gain of $9.62 \mathrm{~dB}$. The radiation characteristics of CMAA are enhanced in the wanted and unwanted directions as depicted by the parameter values of forward power, backward power and FBR. Additionally, the proposed antenna array is giving tremendous virtual size reduction of $77.92 \%$ and better bandwidth of $56.83 \%$. Therefore, the proposed antenna array is a superior performer than CMAA.

\section{Acknowledgment}

None.

Conflicts of interest

The authors have no conflicts of interest to declare.

\section{References}

[1] Ballanis CA. Antenna theory analysis and design. John Willey and Sons Inc., New York. 1997.

[2] Bahl IJ, Bhartia P. Microstrip antennas. Artech house; 1980.

[3] Majewski ML, Rose RW, Scott JR. Modeling and characterization of microstrip-to-coaxial transitions. IEEE Transactions on Microwave Theory and Techniques. 1981; 29(8):799-805.

[4] Christodoulou CG, Wahid PF. Fundamentals of antennas: concepts and applications. SPIE Press; 2001.

[5] Yang F, Rahmat-Samii Y. Electromagnetic band gap structures in antenna engineering. Cambridge University Press; 2009.

[6] Elsheakh DM, Iskander MF, Abdallah EA, Elsadek HA, Elhenawy H. Microstrip array antenna with new 2D-electromagnetic band gap structure shapes to reduce harmonics and mutual coupling. Progress in Electromagnetics Research. 2010; 12:203-13.

[7] Poonia NK, Sherdia KK. Microstrip antenna array for WiMAX \& WLAN applications. International Journal of Advanced Research in Computer and Communication Engineering. 2013; 2(9):3437-40.

[8] Farahani HS, Veysi M, Kamyab M, Tadjalli A. Mutual coupling reduction in patch antenna arrays using a UC-EBG superstrate. IEEE Antennas and Wireless Propagation Letters. 2010; 9:57-9.

[9] Singh A, Sharma K, Sharma V. Microstrip antenna array with i-shaped DGS. International Journal of Recent Research Aspects.2014; 1(2):140-3.

[10] Gupta S and Kumar D. 1:4 Microstrip compact patch antenna array. International Journal of Advanced Research in Computer Science and Software Engineering. 2016; 6(3): 248-51.

[11] Kushwaha N, Kumar R. Study of different shape electromagnetic band gap (EBG) structures for single and dual band applications. Journal of Microwaves, 
Optoelectronics and Electromagnetic Applications. 2014; 13(1):16-30.

[12] Arya AK, Patnaik A, Kartikeyan MV. Back to back combined single feed proximity coupled antenna with dumbbell shaped DGS. Journal of Electromagnetic Analysis and Applications. 2011; 3(2):43-6.

[13] Survase SC, Deshmukh VV. Design of wearable antenna for telemedicine applications. International Journal of Engineering Science and Innovative Technology. 2013; 2(2):574-80.

[14] Shajahan S, Vasuki A. A broadbanding microstrip patch antenna using electromagnetic band gap structures.2017; 116(11):71-9.

[15] Mentor Graphics IE3D User Manual, April 2010.

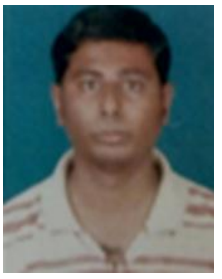

K. Prahlada Rao received his B.E from Osmania University, India and M.E from RMIT University, Australia and currently he is pursuing his $\mathrm{PhD}$ in the field of Microwave Antennas from the department of Applied Electronics, Gulbarga University, Gulbarga. He has 7 research publications in international conferences, 5 in national conferences, 7 in international journals and 3 in book chapters. He has published research papers in Springer, IEEE Xplore, Web of Science indexed journals. His areas of research interests include Microstrip Patch Antennas and Arrays, Electromagnetic Band Gap Structures, Defective Ground Structures.

Email: pra_kaluri@rediffmail.com 